\title{
Tanda Dan Makna Kartun Politik Koran Jawa Pos Tahun 2019
}

\author{
I Wayan Nuriarta \\ Jurusan Desain Komunikasi Visual, Fakultas Seni Rupa dan Desain, Institut Seni Indonesia Denpasar \\ iwayannuriarta@gmail.com
}

\begin{abstract}
Tulisan ini dibuat untuk membaca tanda visual dan tanda verbal yang terdapat pada karya kartun politik Koran Jawa Pos tahun 2019. Pembacaan terhadap tanda tersebut akan digunakan untuk mendeskripsikan makna denotasi dan menggali makna konotasi kartun di tahun politik. Dari sejumlah kartun yang diobservasi, kartun yang terbit pada 13 Januari dan 7 April 2019 dipilih sebagai sampel karena kartun-kartun tersebut menunjukan kartun politik yang menghadirkan kritik terhadap calon presiden serta calon anggota legislatif. Objek penelitian ini difokuskan pada analisis visual kartun, makna denotasi dan makna konotasi. Objek penelitian didasarkan pada analisis makna denotasi dan makna konotasi dengan menggunakan teori semiologi Roland Barthes. Kartun politik yang hadir pada Koran Jawa Pos Minggu tahun 2019 adalah sebuah kartun kritik terhadap calon peserta pemilu yaitu calon presiden dan wakil presiden serta kritik terhadap calon anggota legislatif. Kartun ini memanfaatkan teks visual berupa gambar yang diwarna, dilengkapi dengan teks verbal yang berupa tulisan yang terangkai menjadi kalimat pada satu panel/frame. Teks visual dan teks verbal yang hadir dalam satu panel memunculkan sebuah narasi kritik terhadap persoalan yang diperbincangkan di masyarakat. Pramono sebagai kartunis menggambarkan isu dimasyarakat tersebut dengan gambar yang kritis berbalut nuansa humor.
\end{abstract}

Kata kunci: kartun politik, media massa, semiotika

\section{Signs And Meaning Of Political Cartoons Of Jawa Pos Newspaper In 2019}

This paper is made to read visual signs and verbal signs contained in the work of the political cartoons of Jawa Pos Newspaper in 2019. The reading of the signs will be used to describe the denotation meaning and explore the connotation meaning of the cartoons in the political year. From a number of cartoons observed, the cartoons published on January 13 and April 7, 2019 were chosen as samples because the cartoons showed political cartoons that presented criticism of presidential candidates and legislative candidates. The object of this research is focused on cartoon visual analysis, denotation meaning and connotation meaning. The object of the research is based on the analysis of denotation meaning and connotation meaning using Roland Barthes's semiology theory. The political cartoons were present at the Jawa Pos newspaper on Sundays 2019 were criticism cartoons of candidates for the election, such as the presidential and vice-presidential candidates and criticisms of the legislative candidates. This cartoon uses visual text in the form of colored images, equipped with verbal text in the form of words arranged into sentences in one panel / frame. The visual texts and verbal texts that are present in one panel brought up a critical narrative of the issues discussed in the community. Pramono as a cartoonist described the issue in the community with a critical image wrapped in a sense of humor.

Keywords: political cartoons, mass media, semiotics.

Proses Review : 1 - 20 Agustus 2019, Dinyatakan Lolos: 22 Agustus 2019 


\section{PENDAHULUAN}

Kartun merupakan karya visual yang hadir sebagai bentuk representatif atau simbolik dalam menyampaikan pesan. Secara umum, kartun dapat dibedakan menjadi dua yaitu kartun humor dan kartun politik. Kartun humor adalah sebuah karya kartun yang 'tugasnya' menyampaikan humor saja tanpa muatan politik apapun. Kartun ini juga biasa disebut gag cartoon, tujuan utamanya adalah menghadirkan tawa bagi pembaca. Kartun ini mengangkat humor-humor yang sudah dipahami secara umum oleh masyarakat. Kartun humor biasanya hadir pada media massa dengan tampilan yang sederhana dan "ringan". Sementara kartun politik adalah sebuah karya kartun yang menghadirkan kritik dengan balutan humor di dalamnya. Kartun politik ini biasanya juga disebut sebagai kartun kritik. Kartun ini hadir mengangkat topik tentang situasi politik yang dibuat dengan lelucon. Namun kadang humor tidak sertamerta mampu dibaca cepat karena muatan kritiknya hadir lebih mendominasi pesan. Kritik-kritik yang dihadirkan sangat erat kaitannya dengan kebijakan publik, perilaku tokoh politik dan berbagai peristiwa yang menjadi isu hangat di masyarakat.

Kartun politik sebagai bagian yang integral dari media massa terutama Koran, merupakan salah satu bentuk karya jurnalistik non-verbal yang efektif dan mengena dalam menyampaikan pesan ataupun kritik sosial. Kehadiran kartun pada Koran adalah bentuk reaksi masyarakat (kartunis) dalam menanggapi masalah sosial yang hadir di masyarakat. Dengan bentuk visual atau non-verbal, maka pembaca dirangsang dan didorong secara kreatif mengembangkan berbagai interpretasi sebagai respon terhadap yang diungkapkan oleh kartunis dalam karyanya. Pembaca akan disuguhi dengan tanda-tanda visual dan kata yang penuh dengan perlambangan yang sarat dengan makna. Kehadiran tanda-tanda tersebut merupakan bentuk kretif kartunis dalam memotret persoalan sosial. Visualisasi ini sangat beragam, ada yang menekankan pada kekeliruan, eksagrasi, kejadian-kejadian tidak terduga, satir, parodi dan berbagai pemutarbalikan keadaan.

Koran Jawa Pos sebagai Koran nasional dengan pembaca yang tersebar di berbagai daerah juga menghadirkan kartun pada setiap terbitnya, khususnya yang terbit di hari Minggu. Biasanya Koran Jawa Pos Minggu menghadirkan kartun-kartun humor saja, namun tahun 2019 koran ini menghadirkan kartun politik. Koran Jawa Pos membagi kartun humor dengan kartun kritik/politik dengan judul rubrik yang berbeda meski keduanya sama-sama merupakan karya kartun. Kartun humor dihadirkan pada rubrik kartun, sedangkan kartun kritik dihadirkan pada rubrik sketsa. Hadirnya kartun kritik di tahun 2019 tidak bisa dilepaskan dari alasan bahwa tahun 2019 adalah tahun politik, yaitu tahun diselenggarakannya pemilihan umum secara serentak untuk memilih presiden dan wakil presiden, Dewan Perwakilan Rakyat (DPR), Dewan Perwakilan Rakrat
Daerah Tingkat I (DPRD Provinsi), Dewan Perwakilan Rakyat Daerah Tingkat II (DPRD Kapupaten/Kota) dan pemilihan Dewan Perwakilan Daerah (DPD). Berbagai kegiatan politik terjadi memenuhi berita semua media massa. Kegiatan-kegiatan politik yang dimaksudkan seperti kampanye partai politik maupun kampanye politisi peserta pemilu baik sebagai calon presiden/ wakil presiden, calon anggota DPR, calon anggota DPRD maupun calon DPD. Kegiatan-kegiatan politik ini cendrung menghadirkan suhu politik yang panas di masyarakat karena adanya pilihan politik yang berbeda antara masyarakat yang satu dengan yang lainnya.

Dalam suasana perebutan suara untuk memenangkan partai ataupun kader-kader partai dalam pemilu, maka ada banyak kegiatan politik yang harus mereka lakukan seperti kampanye. Semua kader partai menyerukan hal yang sama yaitu membela rakyat, anti korupsi, memastikan rakyat sejahtera dan banyak janji-janji lainnya jika kadernya terpilih sebagai presiden ataupun wakil rakyat. Menjelang pemilu, slogan-slogan tersebut bermunculan hadir di layar televisi maupun pada sepanduk dan baliho dipinggir jalan. Lawan-lawan politik satu partai juga tak jarang saling sindir, saling menjatuhkan yang bertujuan untuk merebut suara pemilih. Suhu panas tahun politik karena persoalan politik sangat menarik dihadirkan dengan humor lewat kartun.

Pada kartun politik Koran Jawa Pos edisi Minggu ini ditemukan adanya perpaduan unsur kecerdasan, ketajaman kritik, kritis dan ekspresif yang tertuang pada karya visual. Kartunnya menyajikan 'tragedi' dalam 'komedi'. Pembaca disilahkan untuk menginterpretasikan kritik yang dibawa, termasuk di dalamnya disilahkan untuk tertawa atas berbagai peristiwa, juga mentertawakan diri sendiri. Pada penelitian ini akan dibahas teks visual yang berkaitan dengan bentuk, warna, komposisi/layout termasuk cara penggambarannya, teks verbal yang berkaitan dengan dialog tokoh yang digambarkan, serta makna denotasi dan makna konotasi kartun untuk mendapatkan kritik yang disampaikan dalam narasi yang dibangun oleh teks visual beserta teks verbal.

\section{METODE PENELITIAN}

Penelitian ini menggunakan rancangan kualitatif untuk mengumpulkan, menyaring dan menganalisis data. Subjek kajian penelitian ini adalah kartun politik Koran Jawa Pos tahun 2019. Penyeleksian kartun menggunakan teknik penyampelan purposif (purposive sampling). Purposive sampling adalah pengambilan sampel yang disesuaikan dengan tujuan penelitian (Siswantoro, 2010: 73). Dari sejumlah kartun yang diobservasi, kartun yang terbit pada tanggal 13 Januari 2019 dan 7 April 2019 dipilih sebagai sampel karena kartun-kartun tersebut menunjukan kartun politik yang menghadirkan kritik terhadap calon presiden serta calon legislatif. Objek penelitian ini difokuskan pada analisis visual kartun, makna denotasi dan makna kono- 
tasi. Objek penelitian tersebut didasarkan pada analisis makna denotasi dan makna konotasi dengan menggunakan teori semiologi Roland Barthes.

Sebelum penelitian ini dilakukan, peneliti melakukan observasi dan identifikasi awal terhadap kartun-kartun yang ada pada koran Jawa Pos. Data tentang kartun politik dikumpulkan dengan metode observasi dan dokumentasi. Metode Observasi dilakukan pada sejumlah kartun politik pada Koran Jawa Pos. Metode dokumentasi dilakukan dengan membaca sejumlah tulisan yang berkaitan dengan kartun, baik yang berada pada buku teks maupun di media massa.

\section{ANALISIS DAN INTERPRETASI DATA}

Pada pembahasan ini akan diuraikan teks visual dan teks verbal serta makna denotasi dan makna konotasi kartun politik Koran Jawa Pos yang terbit pada edisi 13 Januari 2019 dan 7 April 2019. Kedua kartun ini dipilih karena menunjukan kritik terhadap situasi politik menjelang pemilu 17 April 2019.

Kartun politik Koran Jawa Pos edisi Minggu 13 Januari 2019 hadir pada rubrik sketsa. Kartun ini dibuat oleh kartunis Pramono. Kartun Politik ini memanfaatkan cara bercerita satu panel, artinya kartun tidak menggunakan cara bercerita strips yang menghadirkan transisi panel-panel. Dengan panel yang berukuran $10 \mathrm{~cm}$ x $17 \mathrm{~cm}$, kartun ini menghadirkan teks visual dan teks verbalnya (Gambar1).

Teks visual menghadirkan ilustrasi seorang tokoh yang berbadan gemuk berpakaian warna coklat $(\mathrm{C}=13 \%$, $\mathrm{M}=16 \%, \mathrm{Y}=29 \%, \mathrm{~K}=0 \%$ ). Tokoh ini tampak tersenyum sampai kelihatan giginya. Tangan kanannya menunjukan dua jari yaitu jari tengah dan telungjuk, pun jari kirinya yang berada di belakang punggungnya memperlihatkan hal yang sama. Beberapa orang yang berada di belakang tokoh berbaju coklat ini tampak ramai, ada yang membalas simbol dua jari tersebut dengan ikut mengangkat tangan dan menunjukan dua jari juga. Dihadapan tokoh yang gemuk ini digambarkan tokoh yang kurus. Tokoh kurus ini berada disebelah kanan, menggunakan baju putih $(\mathrm{C}=0 \%$, $\mathrm{M}=0 \%, \mathrm{Y}=0 \%, \mathrm{~K}=0 \%)$ dan bercelana hitam $(\mathrm{C}=76 \%$, $\mathrm{M}=69 \%, \mathrm{Y}=64 \%, \mathrm{~K}=79 \%$. Tokoh berbaju putih ini digambarkan lebih tinggi, dengan senyum yang lebar juga sehingga giginya sangat jelas tergambar. Tokoh ini menunjukan tangan kanannya dengan simbol satu jari yaitu jari telunjuk. Pun tangan kirinya dibelakang punggung juga menunjukan hal yang serupa. Simbol satu jari ditujukan kepada orang-orang yang ada di belakang, yakni yang digambarkan paling kanan pada panel. Orang-orang disanapun tampak ramai, salah satu dari mereka juga membalas dengan ikut menunjukan salam satu jari. Ada juga yang digambarkan membalas dengan jantung. Tokoh berbaju coklat dan berbaju putih ini hadir dalam satu panggung.

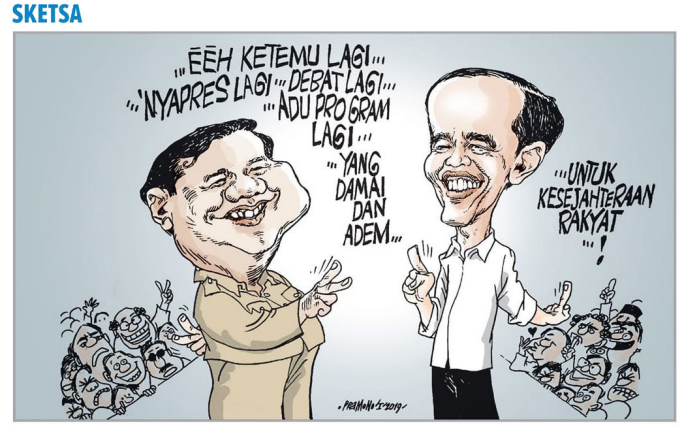

Gambar 1. Kartun Politik Koran Jawa Pos Edisi Minggu, 13 Januari 2019

Teks verbal juga dihadirkan untuk mendukung pesan teks visual. Teks verbal pada kartun ini menggunakan huruf capital berwarna hitam bertuliskan; ,,EEH KETEMU LAGI,,,,, , 'NYAPRES LAGI,,,DEBAT LAGI,,,,, , ADU PROGRAM LAGI,,,,,, YANG DAMAI DAN ADEM,,,. Teks ini dibuat diatas ilustrasi tokoh berbaju coklat dan berakhir diantara dua tokoh utama tersebut, tokoh berbaju coklat dan berbaju putih. Teks verbal yang lain dituliskan pada baian kanan dengan huruf capital berwarna hitam juga yang bertuliskan; ,,,UNTUK KESEJAHTERAAN RAKYAT,,,!. Latar belakang karya dibuat dengan warna biru abu-abu $(\mathrm{C}=28 \%, \mathrm{M}=14 \%, \mathrm{Y}=15 \%, \mathrm{~K}=0 \%$ ) dengan gradasi mengarah pada warna putih ditengah-tengah. Layot yang digunakan mengarah pada penggambaran simetris. Sudut pengambilan gambar menggunakan perspektif sejajar pendangan mata manusia.

Tanda visual dan tanda verbal yang dihadirkan dalam panel menghadirkan makna denotasi. Secara denotasi, kartun ini bermakna bahwa ada dua tokoh utama yang berada di atas panggung, mereka masing-masing berpakaian dengan warna coklat dan yang lain menggunakan pakaian putih hitam. Kedua tokoh tampak gembira berada di atas panggung. Keduanya tersenyum saling menyapa dengan simbol dua jari dan satu jari. Kedua tokoh sama-sama berkata: ehh ketemu lagi, nyapres lagi, debat lagi, adu program lagi, yang damai dan adem. Tokoh berbaju coklat memiliki kemiripan dengan tokoh politik nasional yaitu Prabowo Subianto yang juga merupakan Ketua Umum Partai Gerakan Indonesia Raya (Gerindra). Sedangkan tokoh berpakaian putih hitam, sangat identik dengan calon presiden petahana Joko Widodo yang juga merupakan politisi Partai Demokrasi Indonesia Perjuangan (PDIP) (Gambar 2). Merujuk pada tahun politik tahun 2019, maka dapat disimpulkan bahwa kedua tokoh ini, Prabowo Subianto dan Joko Widodo adalah calon presiden yang merebut panggung di masa kampanye untuk mendapatkan dukungan rakyat agar bisa melaju menduduki kursi presiden. Ajang perebutan suara ini adalah sebuah pesta demokrasi yang harus disambut gembira. Kegembiraan itupun semakin riuh, penuh sorakan dari pendukung di kubu masing-masing. Kedua tokoh utama ini mengajak para pendukung (fanatiknya) di 
belakang mereka. Para pendukung memberikan semangat pada tokoh junjungannya masing-masing.

Makna konotasi kartun ini adalah terpilihnya Prabowo Subianto dan Joko Widodo sebagai calon presiden pada pemilu 2019. Prabowo diusung dan didukung oleh Partai Gerindra, Partai Keadilan Sejahtera (PKS), Partai Amanat Nasional (PAN), Partai Demokrat (PD) dan Partai Berkarya. Dukungan partai pengusung Prabowo Subianto tergabung dalam koalisi Indonesia Adil Makmur. Sementara Joko Widodo diusung dan didukung oleh PDIP, Partai Golkar, Partai Nasional Demokrat (Partai Nasdem), Partai Kebangkitan Bangsa (PKB), Partai Persatuan Pembangunan (PPP), Partai Hati Nurani Rakyat (Partai Hanura), Partai Persatuan Indonesia (Perindo), dan Partai Solidaritas Indonesia (PSI) dalam koalisi Indonesia Maju. Dengan adanya aturan presidential threshold, maka hanya partai politik dengan 20 persen kursi DPR atau 25 persen suara nasional yang bisa mengajukan pasangan calon predisen dan wakil presiden. Partai-partai politik harus berkoalisi untuk bisa memenuhi aturan ini, karena tidak ada satupun partai yang memiliki 20 persen kursi DPR ataupun 25 persen suara nasional. Koalisi partai pun terbangun untuk memenuhi syarat tersebut dengan masing-masing menghadirkan Prabowo Subianto dan Joko Widodo. Menurut sejumlah survey, elaktabilitas Prabowo berada pada urutan kedua setelah calon presiden petahana Joko Widodo. Kedua tokoh ini sebelumnya sudah pernah berhadapan pada "pertarungan" yang sama sebagai calon presiden pada pemilu 2014. Ketika itu, publik terbelah dua antara pro-Prabowo dengan pro-Joko Widodo. Untuk mencegah terjadinya perpecahan dan ketegangan di masyarakat, kartun inipun menuliskan pesannya dalam dialog dua tokoh yang berkompetisi dengan menuliskan kalimat terakhirnya;...... yang damai dan adem.

Dalam catatan media massa menyebutkan bahwa pada kampanye pemilihan presiden 2019 telah memunculkan fenomena yang mencemaskan dengan munculnya perang kata. Dua kubu yang fanatik mendukung calonya masing-masing saling serang setiap hari, strategi kampanye ini terlihat melupakan program-program memajukan kesejahteraan rakyat. Kubu Prabowo menyampaikan serangan dalam pelbagai persoalan, seperti hutang Negara dan daya beli masyarakat yang sangat rendah dengan gaya hiperbol. Pasangan Prabowo yang merupakan calon Wakil Presiden koalisi Indonesia Adil Makmur, Sandiaga Uno pernah melontarkan adanya tempe setipis kartu ATM untuk menggambarkan harga kebutuhan sehari-hari yang semakin mahal. Urusan tempe kemudian menjadi polemik berhari-hari karena kubu pendukung Joko Widodo-Ma'ruf Amin (pasangan calon presiden dan wakil presiden koalisi Indonesia Maju) beraksi untuk memathkan persepsi tersebut. Perang kata pun berlanjut saat calon presiden petahana Joko Widodo melontarkan sindiran kepada politisi lain, yang mengatakan adanya politikus "sontoloyo" saat menanggapi kritik terhadap kebijakan dana kelurahan. Joko Wido-

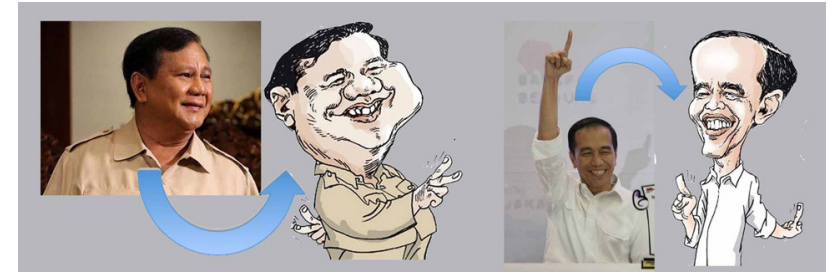

Gambar 2. Kartun wajah tokoh politik. Sumber foto: internet

do juga melemparkan kata; adanya politisi "genderuwo" untuk menyindir kubu lawan yang cendrung menganggap menakut-nakuti rakyat lewat kampanye berbagai isu.

Di zaman ketika media sosial memiliki peran yang signifkan untuk menyebarkan berbagai informasi, perang kata dalam kampanyepun menjadi semakin liar. Baik kubu Prabowo maupun kubu Joko Widodo terus-menerus memproduksi ideom-ideom untuk mengelu-elukan jagoannya atau juga digunakan untuk menyerang lawan. Atas berbagai persoalan yang dilihat, kartun politik karya Pramono yang dihadirkan di Koran Jawa Pos ini mengajak semua lapisan masyarakat untuk selalu damai. Tokoh politik yang berkompetisi diharapkan untuk selalu tersenyum damai menghadapi pemilu 2019. Pesta demokrasi ini harus benar-benar dilihat sebagai sebuah pesta yang menggembirakan untuk semua, mensejahterakan rakyat.

Kartun politik Koran Jawa Pos tidak saja menyampaikan kritik terhadap pemilihan presiden, namun juga menyorot situasi politik kampanye calon anggota legislatif (DPR). Kartun yang hadir pada edisi 7 April 2019 hadir dengan menggunakan satu panel atau satu frame memotret calon anggota legislatif yang menebar janji (Gambar 3). Dengan memanfaatkan panel berukuran $10 \mathrm{~cm} \mathrm{x} 17 \mathrm{~cm}$, kartunis Pramono sedang "bercerita" tentang calon legislatif tahun 2019. Cerita yang dihadirkan adalah narasi untuk menyampaikan opini, karena kartun yang dihadirkan adalah sebuah kartun kritik atas persoalan di tahun politik.

Teks visual yang dihadirkan oleh Pramono sebagai kartunis adalah wujud bunglon berwarna hijau $(\mathrm{C}=42 \%$, $\mathrm{M}=0 \%, \mathrm{Y}=38 \%, \mathrm{~K}=0 \%$ ) pada bagian kiri bidang gambar. Dengan cara membaca (Indonesia) dari kiri ke kanan, atas ke bawah, maka gambar tokoh bunglon ini adalah visual pertama yang tampak. Kepala bunglon dibuat besar berwarna hijau, namun tokoh binatang bunglon digambarkan memakai jas berwarna kecoklatan $(\mathrm{C}=14 \%, \mathrm{M}=8 \%$, $\mathrm{Y}=21 \%, \mathrm{~K}=0 \%$ ), memakai dasi hitam $(\mathrm{C}=70 \%, \mathrm{M}=68 \%$, $\mathrm{Y}=64 \%, \mathrm{~K}=74 \%$ ) dengan celana dan sepatu hitam. Ekor binatang bunglon tetap kelihatan. Tokoh ini membawa selembar kertas yang berisi teks verbal bertuliskan: $J A N$ JI2 yang dapat dibaca membawa janji-janji. Di atas kepala tokoh bunglon terdapat titik-titik membentuk lingkaran. Dalam bentuk lingkaran tersebut digambarkan kursi ber- 


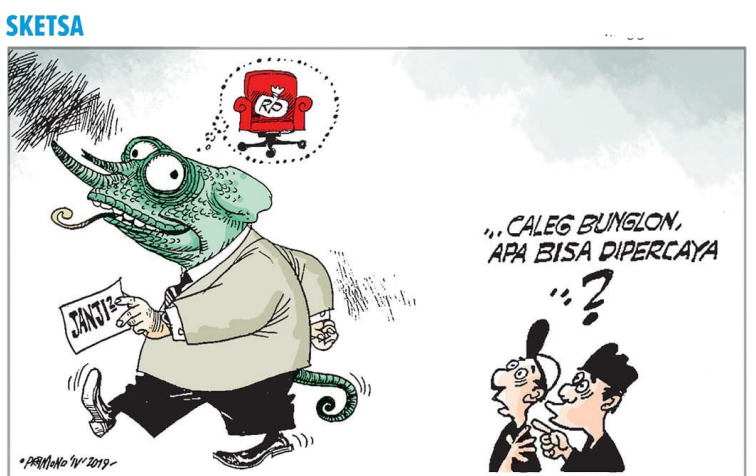

Gambar 3. Kartun Politik Koran Jawa Pos Edisi Minggu, 7 April 2019)

warna merah $(\mathrm{C}=0 \%, \mathrm{M}=97 \%, \mathrm{Y}=97 \%, \mathrm{~K}=0 \%)$. Kursi yang digambarkan tampak sangat nyaman jika diduduki. Pada kursi diisi gambar kantong berisi huruf RP yang menunjukan Rupiah, mata uang Indonesia.

Disebelah kanan digambarkan dua tokoh yang seolah berbincang. Kedua tokoh itu tampak melihat tokoh bunglon dengan penuh keraguan. Dua tokoh ini digambarkan dengan wajah berwarna coklat muda $(C=0 \%, M=19 \%$, $\mathrm{Y}=23 \%, \mathrm{~K}=0 \%$ ). Tampak digambarkan tokoh paling kanan menunjuk kearah tokoh bunglon sebagai penegasan bahwa mereka sedang fokus melihat tokoh bunglon yang sedang membawa kertas bertuliskan JANJI2. Diatas kepala dua tokoh ini terdapat teks verbal yang bertuliskan: ,,,CALEG BUNGLON, APA BISA DIPERCAYA,,,?

Dengan menghubungkan teks visual dan teks verbal yang digambarkan, maka makna denotasi kartun satu panel ini dapat dibaca sedang berkisah tentang tokoh Bunglon yang ingin duduk nyaman di kursi kekuasaan sebagai wakil rakyat. Tokoh bunglon tampak gelisah, dan pergi kesana kemari membawa janji-janji yang dilontarkan kepada masyarakat. Bunglon melakukan kampanye dengan tawaran berbagai janji. Bunglon digunakan sebagai metafora tokoh Calon Legislatif (Caleg) tahun 2019. Penampilan sebagai seorang Caleg juga ditunjukan dengan pakaian yang ia gunakan yaitu memakai jas, dasi dan sepatu yang mengkilap sebagai simbol 'kemapanan'. Badan bunglon digambarkan gemuk, tampak dari badannya yang lebar. Bola mata caleg bunglon tampak melirik dua tokoh lain yang ada di sebelah kanan. Sementara dua tokoh yang digambarkan dalam ukuran yang jauh lebih kecil dari caleg bunglon juga melihat sikap dan tingkah laku bunglon. Dua tokoh ini sedang membicarakan caleg bunglon. Mereka meragukan kinerja caleg bunglon jika seandainya bunglon bisa duduk di kursi DPR.

Makna konotasi kartun ini adalah mengkritik para calon anggota legislatif yang berlaga dengan janji-janji palsu pada pemilu 2019. Pada pemilu 2019 terdapat 320 ribu calon anggota legislatif yang berlaga mencari pemilih. Kartun ini menggunakan metafora binatang bunglon se- bagai seorang calon anggota legislatif. Metafora tersebut menyampaikan pesan pada pembaca bahwa binatang bunglon adalah binatang yang mudah mengubah warna kulitnya. Bunglon sebagai salah satu calon legislatif adalah makhluk yang mudah berubah sesuai dengan tempat lingkungannya berada. Mampu mengubah warna kulit adalah senjata bunglon. Secara ilmu biologi, rahasia kemampuan mengubah warna kulit karena nanokristal pada kulitnya. Nanokristal ini memantulkan cahaya dan perubahan ruang antara kristal juga mengubah cahaya apa yang dipantulkan ke mata kita.

Bunglon merupakan salah satu hewan "eksotis" berbentuk kadal yang hidup di pohon. Sebagai makhluk yang pandai beradaptasi, mengelabui dan bersembunyi. Bunglon pada kartun ini hadir dengan penuh strategi untuk mencari pendukung agar bisa terpilih sebagai anggota dewan yang terhormat. Bunglon sebagai Caleg sangat berharap akan bisa duduk di kursi DPR yang nyaman. Dengan menduduki kursi DPR, bunglon berpikir akan bisa mendapatkan uang yang banyak karena gaji besar dan mendapatkan banyak tunjangan. Kemewahan atas kursi kekuasaan yang ia miliki akan membawa kebahagiaan untuk dirinya sendiri. Semua tipu muslihat/ tipu daya akan digunakan caleg bunglon agar terpilih.

Bunglon menjadi gambaran visual tokoh caleg yang ingin menduduki kursi DPR. Tokoh yang memiliki sifat suka mengelabui ini juga berarti bahwa ada caleg yang selalu membawa jani-janji saja menemui rakyat pemilih. Hanya janji-janji kosong tanpa pernah bekerja untuk rakyat yang diwakilinya. Janji-janji selalu disampaikan saat menjelang pemilihan, namun semua janji akan dengan cepat terlupakan saat caleg sudah duduk di kursi empuk. Para caleg bunglon akan diam saja menikmati kemewahan, sering mangkir dari tugas dan tanggungjawab. Maka sosok caleg bunglon adalah sosok yang penuh tipuan demi keuntungannya sendiri dan lupa pada tugasnya untuk memberikan kesejahteraan bagi rakyatnya. Sementara pada gambar di sebelah kanan dalam panel tampak dua tokoh dengan tubuh yang kurus sedang memandang caleg bunglon. Kedua tokoh tersebut dapat dibaca sebagai representasi rakyat kecil, yaitu rakyat yang memiliki hak suara untuk memilih caleg. Rakyat ini mempertanyakan kinerja caleg bunglon. Pada gambar secara visual menunjukan rakyat ini melontarkan kata-kata “,,,Caleg Bunglon, Apa Bisa Dipercaya,,,? Rakyat sangat sangsi akan kinerja caleg karena caleg bunglon diketahui memiliki niat yang tidak baik. Caleg bunglon ini hanya ingin kekuasaan, hanya berniat memperkaya diri sendiri.

Kartun kritik yang hadir di tahun politik ini tidak saja menyampaikan kritik terhadap para caleg yang memiliki sifat bunglon, namun juga memiliki saran, ajakan kepada seluruh rakyat agar tidak memilih caleg bunglon. Caleg yang tidak memiliki kinerja baik atau rekam jejak yang buruk harusnya tidak dipilih sebagai wakil rakyat. Rakyat 
harus jeli melihat rekam jejak calon wakil rakyat. Rakyat diajak untuk lebih melek informasi terhadap wakil-wakil rakyat yang sedang menjadi caleg. Tentu harapan ini sejalan juga dengan keinginan masyarakat Indonesia untuk menghadirkan wakil-wakil rakyat yang dapat dipercaya menentukan kebijakan demi kepetingan bersama, yaitu masyarakat maju, adil dan makmur. Harus diakui bahwa tidak mudah mencari 'orang baik' sekaligus berkualitas dari ribuan caleg yang berlaga. Kesulitan ini sekaligus juga menggambarkan buruknya rekrutmen partai politik dalam memilih calon wakil rakyat yang akan duduk di DPR. Partai cendrung mengutamakn loyalitas, pola transaksional dalam merekrut calon masih terjadi di banyak partai.

\section{SIMPULAN}

Kartun politik yang hadir pada Koran Jawa Pos Minggu tahun 2019 adalah sebuah kartun kritik terhadap calon peserta pemilu yaitu calon presiden dan wakil presiden serta kritik terhadap calon anggota legislatif. Kartun ini memanfaatkan teks visual berupa gambar yang diwarna, dilengkapi dengan teks verbal yang berupa tulisan yang terangkai menjadi kalimat pada satu panel/frame. Teks visual dan teks verbal yang hadir dalam satu panel memunculkan sebuah narasi kritik terhadap persoalan yang diperbincangkan di masyarakat. Pramono sebagai kartunis menggambarkan isu dimasyarakat dengan gambar yang kritis berbalut nuansa humor. Kartun yang hadir pada 13 Januari 2019 menghadirkan debat calon presiden yang diramaikan oleh para pendukungnya. Kartun ini mengingatkan pada para pendukung agar selalu menghadirkan suasana damai dan adem. Diketahui bahwa masing-masing pendukung, baik pro Prabowo maupun pro Joko Widodo memiliki pendukung fanatik masing-masing. Kartun ini mengharapkan agar suasana kampanye selalu damai dan adem sampai pemilu dan seterusnya. Masyarakat diharapkan tetap damai menyambut pesta demokrasi yang selalu datang tiap 5 tahun. Pun para elit politik diharapkan selalu hadir dengan senyum ceria, bukan hadir dengan narasi-narasi yang dapat memanaskan tensi politik tanah air.

Disisi lain, kartun yang hadir pada 7 April 2019 menggambarkan tokoh caleg bunglon yang kemana-mana membawa janji-janji untuk meyakinkan pemilih. Caleg bunglon menjadi tokoh sentral pada kartun ini. Tampak sangat jelas kritik yang dibangun adalah kritik pada para caleg yang memiliki sifat bunglon, yaitu caleg yang penuh tipu muslihat dan mudah melupakan janji. Dengan hadirnya kartun ini, masyarakat diingatkan agar selektif memilih wakil rakyat. Masyarakat pemilih dijak untuk tidak memilih caleg yang hanya mengobral janji namun minim bukti. Masyarakat diajak untuk melihat rekam jejak masing-masing caleg agar tidak salah pilih. Harapan untuk menghadirkan wakil rakyat yang benar-benar bekerja untuk rakyat adalah harapan kita semua.

\section{DAFTAR RUJUKAN}

Adnyana, I. W., Rai Remawa, A. A. G., \& Desi In Diana Sari, N. L. (2019). Metafora Baru dalam Seni Lukis Kontemporer Berbasis Ikonografi Relief Yeh Pulu. Mudra Jurnal Seni Budaya, 34(2), 223-229. Retrieved from https:// jurnal.isi-dps.ac.id/index.php/mudra/article/view/704

Nuriarta, I. W., \& Bayu Artha, I. G. A. I. (2017). Bahasa Rupa Kartun Konpopilan Pada Koran Kompas Tahun 2016. Jurnal Hasil-Hasil Penelitian Institut Seni Indonesia Denpasar, 5. Retrieved from https://jurnal.isi-dps. ac.id/index.php/segarawidya/article/view/191

Piliang, Yasraf Amir. (2012). Semiotika dan Hipersemiotika. Bandung : Matahari

Sibarani, Augustin. (2001). Karikatur dan Politik. Jakarta: Institut Studi Arus Informasi.

Siswantoro. (2010). Metode Penelitian Sastra: Analisis Struktur Puisi. Yogyakarta: Pustaka Pelajar.

Sunarto, Priyanto.dkk. (2019). Metafora Visual: Kartun Editorial Pada Surat Kabar Jakarta 1950-1957. Jakarta: IKJ Press.

Tinarbuko, S. (2019). Membaca Makna Iklan Politik Pilpres 2019. Mudra Jurnal Seni Budaya, 34(2), 250-258. Retrieved from https://jurnal.isi-dps.ac.id/index.php/ mudra/article/view/707

Wijana, I Dewa Putu. (2003). Kartun. Yogyakarta: Ombak 